\title{
Ocean carbon sequestration by fertilization: An integrated biogeochemical assessment
}

\author{
Grant DE-FG03-00ER63010 \\ DOE Office of Biological and Environmental Research
}

\author{
FINAL REPORT \\ PRINCETON UNIVERSITY \\ Jorge L. Sarmiento, PI \\ Anand Gnandesikan, Co-PI \\ UNIVERSITY OF CALIFORNLA, LOS ANGLES \\ Nicolas Gruber, PI
}

\section{Overview}

This final report summarizes research undertaken collaboratively between Princeton University, the NOAA Geophysical Fluid Dynamics Laboratory on the Princeton University campus, the State University of New York at Stony Brook, and the University of California, Los Angeles from 09/01/2000 to 08/31/2004 sponsored by DOE's and entitled "Ocean carboil sequestration by fertilization: An integrated biogeochemical assessment".

Under this grant, we investigated a range of issues associated with the proposal to fertilize the ocean with nutrients (such as iron) in order to increase the expon of organic matter from the ocean's near surface waters and consequently increase the uptake of $\mathrm{CO}_{2}$ from the atmosphere. There are several critical scientific questions that have the potential to be make-orbreak issues for this proposed carbon sequestration mechanism:

(1) If iron is added to the ocean, will export of organic carbon from the surface actually occur? Clearly, if no export occurs, then there will be no sequestration.

(2) If iron fertilization does lead to export of organic carbon from the surface of the ocean, how much $\mathrm{CO}_{2}$ will actually be removed from the atmosphere? Even if carbon is removed from the surface of the ocean, this does not guarantee that there will be significant removal of $\mathrm{CO}_{2}$ from the atmosphere, since the $\mathrm{CO}_{2}$ may be supplied by a realignment of dissolved inorganic earbon within the ocean.

(3) What is the time scale of any sequestration that occurs? If sequestered $\mathrm{CO}_{2}$ returns to the atmosphere on a relatively short time scale, iron fertilization will not contribute significantly to slowing the growth of atmospheric $\mathrm{CO}_{2}$.

(4) Can the magnitude of sequestration be verified? If verification is extremely difficult or impossible, this option is likely to be viewed less favorably.

(5) What unintended consequences might there be from fertilizing the ocean with iron? If these are severe enough, they will have a significant impact on policy decisions. Most research on carbon sequestration by fertilization has focused on the first of these issues. Although a number of in situ fertilization experiments have successfully demonstrated that the 
addition of iron leads to a dramatic increase in ocean productivity, the question of whether this results in enhanced export remains an open one. The primary focus of our research was on the development of models to examine topics (2) through (5), although some of the research we accomplished has implications for the first of these topics as well. In the following we present and discuss our main results and products.

We start with a discussion of our results from large-scale fertilization experiments using a relatively simple ecosystem model, While these experiments are very instructive in highlighting the mechanisms and consequences, it is very unlikely that fertilization will ever be carried out on such scales. We therefore conducted a detailed study to investigate how patch-scale fertilization differs from that conducted at basin scale. After presenting the results of this study, we then discuss the results we obtained with regard to consequences of fertilization on ocean biogeochemistry and radiative forcing. Since the existing ecological/biogeochemical models at the beginning of our grant were not adequate to investigate many important components of how ocean ecology and biogeochemistry will respond to the addition of iron, a substantial fraction of our efforts went also into the development of a model that would allow us to quantitatively predict phytoplankton functional group diversity. After reporting on our model development work, we close with a summary of our outreach activities and publications.

Note: Publications supported by this grant are identified by italics.

\section{Large Scale Fertilization}

When we began this project, we were thinking almost exclusively in terms of long-tem fertilization over large regions of the ocean such as the Southern Ocean, with much of out concern being on how the ocean circulation would control the response to a given fertilization scenario. Early on in our project, it became clear that small "patch-scale" fertilizations over limited regions of order $100 \mathrm{~km}$ diameter were much more likely. We describe here the largescale fertilization simulations we carried out, and discuss patch scale fertilization simulations in the following section.

We assumed that iron addition is able to cause macronutrient depletion and applied such depletion over different basins in a set of model simulations (Marinov et al, in prep-b). Because of the circulation characteristics and large concentration of unused surface nutrients in the Southem Ocean, depleting nutrients in this area results in much higher atmospheric $\mathrm{CO}_{2}$ drawdown than depleting nutrients in the North Atlantic, North Pacific, or tropical ocean. confiming earlier work on this problem (Sarmiento \& Orr, 1991).

Based on four sets of simulations, in which isopycnal and diapyenal diffusivity coefficients were varied in the tracer equations (Gnanadesikan el al., submined), resulting in very different circulation scenarios, we found that depleting nutrients results in similar sequestration of $\mathrm{CO}_{2}$ despite large variations in the productivity and nutrient profiles (Marinov of al. 2003, in prep -a). This surprising result is due in part to how the rest of the ocean responds to Southern Ocean fertilization. Complete removal of macronutrients in this region results in the remowal of the performed nutrients that are usually transported into the low latitudes (Samiento 


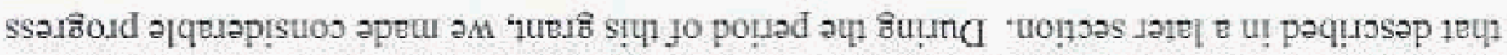

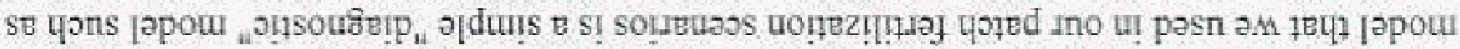

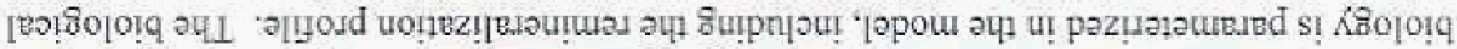

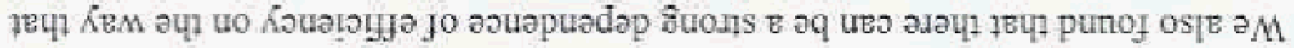

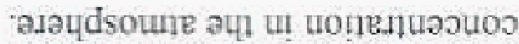

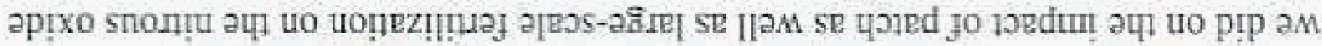

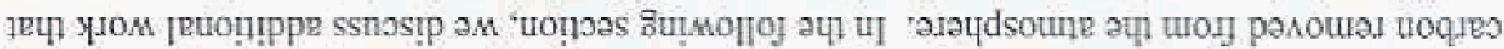
jo to1- I G1asa $10 \mathrm{~g}$ Kun

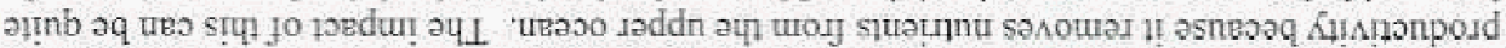

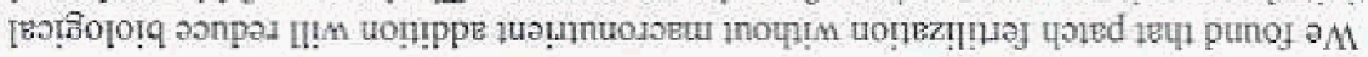

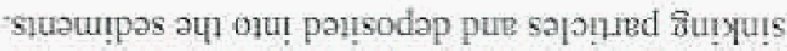

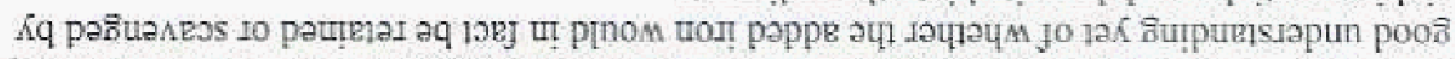

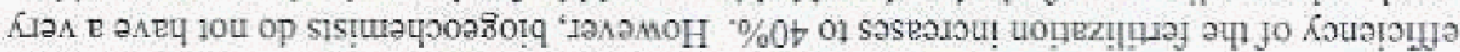

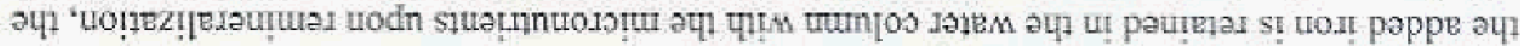

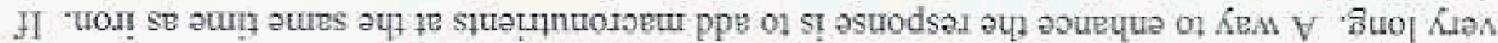

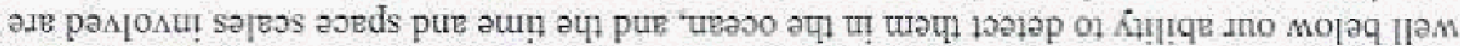

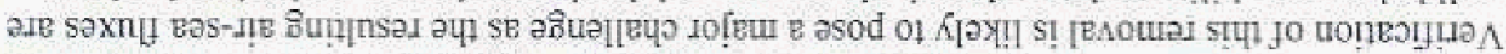

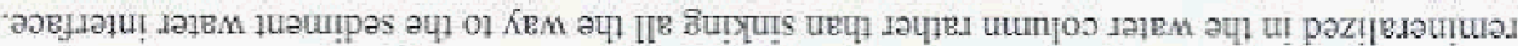

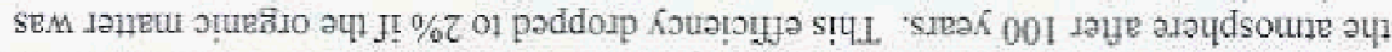

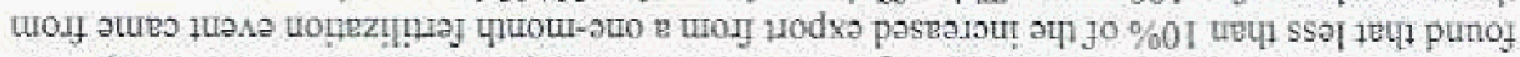

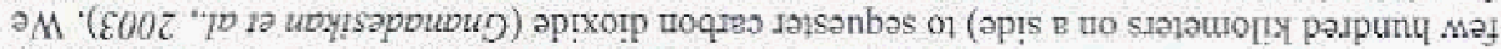

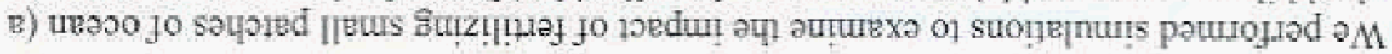

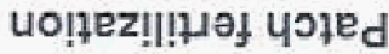

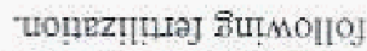

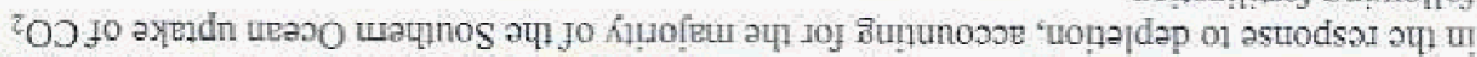

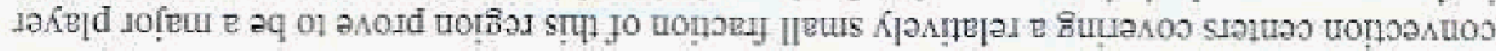

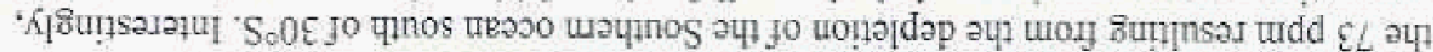

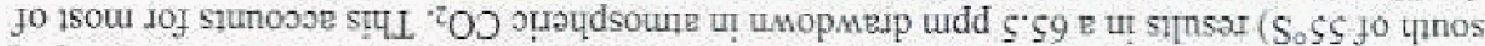

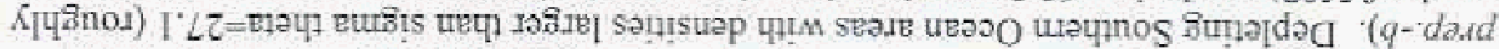

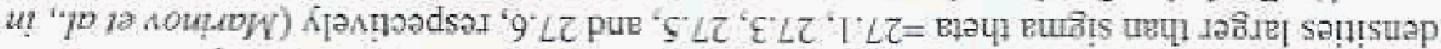

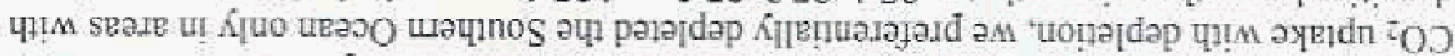

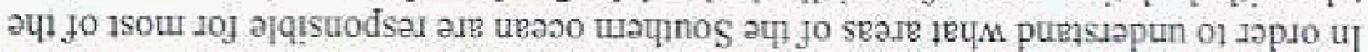

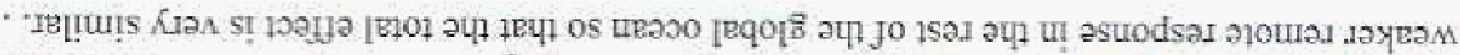

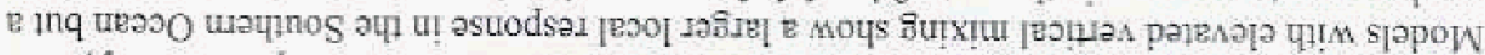

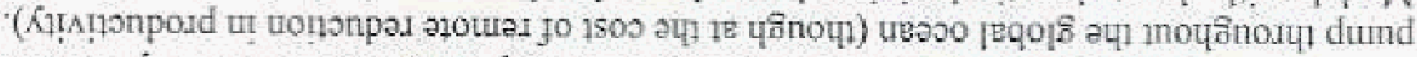

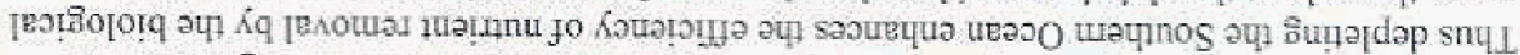

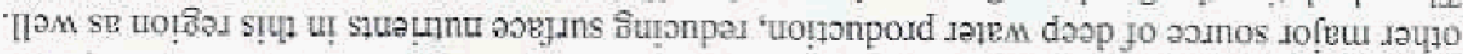

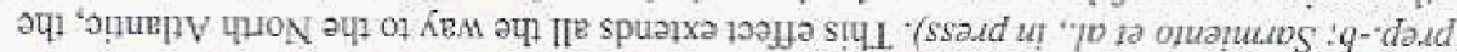

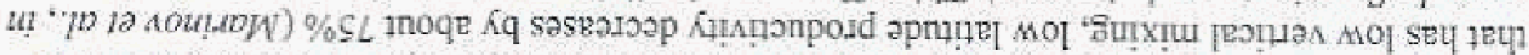

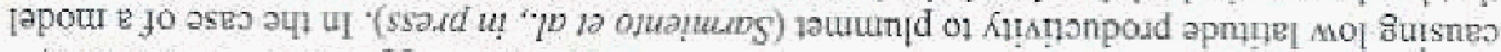

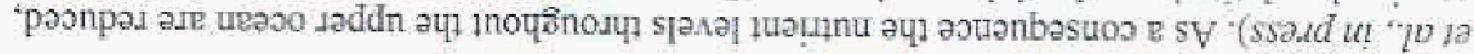


on the background work required to develop a more realistic model. With the renewal of this grant, we are now in the final stages of implementing this model and will use it to re-examine the patch fertilization scenarios.

\section{Biogeochemical Consequences of Fertilization}

The expected increase in the export of organic material from the surface ocean into the interior as a consequence of a successful fertilization will result in enhanced rates of remineralization in the deeper layers of the ocean. Fuhman and Capone (1991) pointed out that such an increase in remineralization will likely enhance production of nitrous oxide, that, when emitted into the atmosphere, will result in some offset of the radiative benefit of the atmospheric $\mathrm{CO}_{2}$ reduetion stemming from the fertilization. This potential feedback is particularly worthwhile investigating since $\mathrm{N}_{2} \mathrm{O}$ is 200 times more radiatively active than $\mathrm{CO}_{2}$.

We investigated the consequences of iron fertilization on oceanic $\mathrm{N}_{2} \mathrm{O}$ emissions with our diagnostic biological model, to which we added a simple description of the $\mathrm{N}_{2} \mathrm{O}$ cyele following Sum haralingam (1997) (Jin and Gruber, in press). We separately considered the nitrification and low oxygen mechanisms that are known to produce $\mathrm{N}_{2} \mathrm{O}$. As the relative role of these processes are not well known, we set up two simulations, one considering the nitrification pathway only and the second considering the low oxygen pathway only. As the tracer equation is linear we can combine the resulis of these extreme cases to obtain any intermediate case. Our "best estimate" case is that which assumes that about half of the global oceanic production of $\mathrm{N}_{2} \mathrm{O}$ comes from the nitrification pathway, and the other half from the low oxygen pathway. This best estimate is based on the studies of Stmharalingan and Sarmiento (2000) and our own extensive comparison of our model results with in situ data (Jin and Gruber, in prep). We conducted large-scale and patch fertilization experiments in the tropics, the Southem Ocean, the Northem North Pacific Ocean and the Northem North Atlantic Ocean. We further considered a fertilization of 10 year duration, followed by 90 years without fertilization and a fertilization of 100 year duration.

We found that the magnitude of the warming offset caused by nitrous oxide release to the atmosphere is substantial, but is highly dependent on the location and duration of fertilization (Jin and Gruber, in press). The largest offiset (of the order of $100 \%$ ) is found when fertilization is undertaken in the tropics, particularly when it is of limited duration and size. Smaller, but still substantial effects are found when fertilization is undertaken elsewhere and over longer periods. These results suggest that any assesment of ocean fertilization as a mitigating option is incomplete without consideration of the $\mathrm{N}_{2} \mathrm{O}$ feedback.

The oceanic oxygen concentrations play a key role in controlling the magnitude of the $\mathrm{N}_{2} \mathrm{O}$ feedback, due to the very high $\mathrm{N}_{2} \mathrm{O}$ yields occurring at low oxygen concentrations (Jin and Gruber, in prep). The low oxygen concentration found in the themocline of the tropical ocean makes this region the most sensitive one with regard to the magnitude of the $\mathrm{N}_{2} \mathrm{O}$ feedback. The substantial reduction of the thermocline oxygen concentration in the North Pacific as a result of the long-term fertilization turns this region from one whose $\mathrm{N}_{2} \mathrm{O}$ formation mechanism is dominated by the nitrification pathway to one dominated by the denitrification pathway, highlighting the non-linear response of the system. 
As discussed above for the Southern Ocean, a second important consequence of iron fertilization is the decrease of primary production in regions outside those that are fertilized (Gnamadesihon et al, 2003; Samiento et al, in press; Marinov at al., in prep-b). Interestingly, this decrease is another reason why the magnitude of the $\mathrm{N}_{2} \mathrm{O}$ feedback is smallest in the Southern Ocean, as this decrease in the low latitude production actually reduces the $\mathrm{N}_{2} \mathrm{O}$ production in the low latitudes, where yields tend to be high, leading to quite a substantial offset in the increased $\mathrm{N}_{2} \mathrm{O}$ production in the Southem Ocean (Nin and Gruber, in press).

\section{Model Development}

The existing ocean biogeochemistry/ecology models at the onset of this project were insufficient to address many of the detailed questions associated with the role of upper oceani ecosystem structure in determining the response of the ocean to nutrient fertilization. In particular, we suggested that the oceanic response to iron fertilization would depend very strongly on the specifie response of the main phytoplankton functional groups. For example, the impact of increased productivity on the air-sea balance of $\mathrm{CO}_{2}$ would depend on the relative ratio of organisms that produce $\mathrm{CaCO}_{3}$ shells (hypothesized to be due mainly to coccolithophorids) and those that just produce organic matter. The most important group of species in the latter group are diatoms, which require silicic acid to grow. Since the formation of $\mathrm{CaCO}_{3}$ increases the partial pressure of $\mathrm{CO}_{2}$, a replacement of coccolithophorids by diatoms or some other phytoplankton while keeping export production the same would lead to a sequestration of $\mathrm{CO}_{2}$ from the atmosphere. We have proposed such a mechanism to explain in part the observed change in atmospheric $\mathrm{CO}_{2}$ between the last glacial maximum and today (Brzezinski et al, 2002; Matsumoto et al., 2002), but an assessment of the impact of such changes in ecology on humanscale ocean iron fertilization requires a detailed predictive model that includes such phytoplankton functional group diversity explicitly. No such model existed at the onset of our project. We proposed to develop such a model in three stages:

- A diagnostic biogeochemical model, in which all the nutrients and alkalinity are forced towards the observed fields at the surface of the ocean.

- A semi-prognostic biogeochemical model, in which only phosphate is forced towards observations at the surface of the ocean, and export is predicted by a set of ecological rules.

- A fully prognostic model, which explicitly models phytoplankton dynamics through light and nutrient limitation:

We made considerable progress on all three of these modeling approaches and discuss each of them in turn. With the renewal of this grant, we are now in the final stages of implementing these models and will use them for a new set of fertilization scenarios that we expect will settle many of the issues that were raised by our earlier studies.

\section{1.) Diagnostic biogeochemistry}

In this model, we infer biological productivity from the physical supply of nutrients through the mismatch between modeled and observed surface nutrient fields. By separately modeling nitrate, phosphate, silicate, alkalinity and iron, we infer the stoichiometry of elemental fluxes. Previous runs done at Princeton have had a very simple relationship between production and export. We have developed a new diagnostic model of biogeochemical cycling which takes 
advantage of the large amount of data collected during the past decade relating primary production to export, as well as distributions of dissolved organic matter (cf., Jin et al, in prep.). This model starts by restoring surface phosphate towards observations and then uses a simple ecosystem (Dume et al, stubmitted. GBC) to allocate the diagnosed total production to small and large phytoplankton). Phosphorus surplus is used to diagnose nitrogen fixation in the surface while anoxic remineralization is used to diagnose denitrification in the interior (Deutsch 2003). The contribution of diatoms and coccolithophonds to the large phytoplankton production is determined by converting the diagnostically inferted opal and $\mathrm{CaCO}_{3}$ productions into organic nitrogen production. This model allows us to infer the partitioning of organic productivity into sinking material, tegenerated nutrients and dissolved otganic material and compare our estimates of productivity with satellite observations of ocean color (Dunne et al. 2002. Eos Trans).

We have coupled the cycling of particulate organic material in the water column to that of silicon and alkalinity through the inclusion of the protection of sinking organic material by opal and calcium carbonate ballast, allowing us to reproduce the global constancy in the carbon content in sinking material collected in deep sediment traps (Dunne et al., in prep.-b). Our preliminary results show a global organic carbon production of $13.9 \mathrm{Pg} \mathrm{Cyr}, \mathrm{a} \mathrm{CaCO}$ production of $1.16 \mathrm{Pg}$ C/yr and an opal production of $188 \mathrm{~T} \mathrm{~mol} \mathrm{Si/yr.} \mathrm{The} \mathrm{implied} \mathrm{export} \mathrm{ratios}$ of inorganic carbon to organic earbon are about $0.08: 1$, consistent with the vertical ratio analysis of Sarmiento et al. (2002) (see below). Small phytoplankton afe found to dominate, with more than $75 \%$ of global production associated with this functional group. Their dominance is particularly strong in the low latitudes. Among the large phytoplankton, the diatoms, coccolithophorids and other large phytoplankton contribute roughly equally to NPP. As expected, diatoms tend to dominate at high latitudes, where they make up more than $40 \%$ of the large phytoplankton production. Equatorward of the diatom-dominated belt, coecolithophorids are dominant. A paper on this topic is curtently in preparation (Jin et al. in prep.).

In our attempt to characterize the cycling of dissolved organic matter, we found the inclusion of differential production or regeneration of dissolved organic material (DOM) critical in reproducing observed meridional trends. Specifically, production in the oligotrophic regions of DOM was inferred to be either a much larger fraction of the total production, or much longerlived. We are using new support to continue experimenting with various mechanistic formulations of the sinking detrital pool to investigate controls on remineralization in the ocean interior including such effects as the protection of organic material by mineral ballast, temperature, lability, sinking velocity and zooplankton grazing (Dwme ef al, in preb.-b).

\section{J Semi-prognostic biogeochemistry}

We developed a first version of this model, but put this project on hold until we could complete analysis of the diagnostic model to develop an improved model for prediction of stoichiometric ratios. A specific result from this study was the necessity for including variable $\mathrm{Si} \mathrm{N}$ ratios in any prognostic model. In particular, unless we simulate the unusually high Si:N drawdown ratios of Southem Ocean iron limited production, we predict excessive silicic acid concentrations in low latitudes and an unrealistic domination of diatoms at all latitudes ( $c$., Brzezinski et al., 2002; Matsumoto et al. 2002; Sarmiento et al., in press). 


\section{3.)Prognostic model development}

The prognostic version of the model, which we expect to complete by early next year with the renewal of this grant, builds on the two previous models by incorporating explicit phytoplankton growth with a simple light penetration model. It includes three phytoplankton groups: small (patterned after cyanobacteria with coccolithophonids also included as a fixed fraction of the small phytoplankton), large (patterned after diatoms) and diazotrophic (patterned after trichodesmium) (Dume et al, stomitted). Phytoplankton growth rates are determined as a function of temperature, light and mutrient limitation as well the $\mathrm{C}: \mathrm{Chl}$ ratio in phytoplankton which is allowed to vary instantaneously after the Geider et al. (1996) model of equilibrium carbon and nutrient uptake. Nutrient limitation is expressed using Liebig's law of the minimum by nitrate, ammonia, phosphate, silicate and iron. Nitrogen limitation includes ammonia inhibition and nitrogen fixation by diazotrophs. The export and remineralization parameterizations developed with the diagnostic model (cf., Dumne et al., submitted, and Dunne et al, in prep-b) are implemented to predict the export and fate of organic matter.

\section{Analyses of Observations and Models}

As part of our efforts to develop improved models of ocean ecology and to test thase models, we did several combined model-data analysis studies of how export from the surface of the ocean is related to the primary production, and what the $\mathrm{CaCO}_{3}$ and diatom opal to organic carbon export ratios are around the world. The response of the ocean to a fertilization event will depend greatly on the nature of the organisms that carry out the enhanced production, and their ability to export organic matter from the surface of the ocean. The information gained from these studies provided major insights that were or are being incorporated into our models.

\section{1.) Particle export ratio}

Iron fertilization experiments in waters with unutilized nutrient have unfailingly shown an increase in primary production, yet have failed so far to clearly demonstrate an increase in export (Nodder and Waite, 2001). Is this \& result of incomplete observations, or are there reasons to expect that the additionally fixed nutrients merely cycle more rapidly within the mixed layer? This question can be cast in terms of the pe-ratio, the ratio of particulate export to primary production.

We have synthesized observations of the particle export ratio and used this synthesis to calibrate empirical algorithms of the particle export ratio as a function of the log of biomass (or productivity) and temperature (Dunne et al., submitted, GBC). We also developed a predictive, ecosystem-based model of the pe-ratio as it varies in space and time through temperature, and productivity through changes in phytoplankton size structure and mineral ballast protection of sinking detritus. The model is driven by the difference in the functional form of the grazing loss. term and export efficiencies between large phytoplankton (where grazing is proportional to the four-thirds power of efficiently-exported biomass) and small phytoplankton (where grazing is proportional to the second power of inefficiently-exported biomass). We demonstrate that both the empirical regression and the simple ecosystem size-based model reproduce the observed variability in pe-ratios (Dunne et al., submitted).

This simple ecosystem model has been implemented within the diagnostic ocean 
biogeochemistry model described in the previous section. This model is able to reproduce major pattems in primary production as interpreted from satellite-based estimates of ocean color, surface irradiance, temperature and euphotic zone depth. Important differences exist, however, which point to deficiencies in the model's representation of ocean circulation, our biological representation of ocean ecosystems, and the satellite chlorophyll and primary productivity algorithms.

\section{2.) A new estimate of the $\mathrm{CaCO}_{3}$ to organic carbon export ratio}

We used an ocean biogeochemical-transport box model of the top $200 \mathrm{~m}$ of the water column to estimate the $\mathrm{CaCO}_{3}$ to orgatic carbon export ratio from observations of the vertical gradients of potential alkalinity and nitrate (Samieno el al, 2002). We found a global average molar export ratio of $0.06+/-0.03$. This is substantially smaller than earlier estimates of 0.25 on which a majority of ocean biogeochemical models had based their parameterization of $\mathrm{CaCO}_{3}$ production. Contrary to the pattern of coccolithophore blooms deternined from satellite observations, which show high latitude predominance, we found maximum export ratios in the equatorial region and generally smaller ratios in the subtropical and subpolar gyres. Our results suggest a dominant contribution to global calcification by low-latitude non-bloom forming coccolithophores or other organisms such as foraminifera and pteropods.

\section{3.) A new estimate of the opal to organic carbon export ratio}

We used the same box model employed for estimating the $\mathrm{CaCO}_{3}$ to organte carbon export ratio (see above) to estimate the opal to organic nitrogen (and thereby, carbon) export ratio from observations of the vertical gradients of silicic acid and nitrate (Sommiento et al., in press). This study shows that the Southem Ocean has exceptionally high export ratios that result in a complete depletion of silicic acid in waters that are still rich in mitrate. The export of this water to the north explains the low concentration of silicic acid in much of the rest of the world. Including this in models is cssential to correctly simulating diatom production, as noted previously.

\section{4.) A new estimate of global particle export and remineralization of the major elements}

We have used our particle export ratio estinates in conbination with satellite based estimates of primary production to calculate export production of organic carbon in the world ocean. These export production maps have been used to test our model simulations (Gnanadesikan, et al., submitted). The box model method that we employed to estimate the $\mathrm{CaCO}_{3}$ and opal to organic carbon export ratios can also be used to estimate the export ratios of the other macronutrients (nitrogen and phosphorus). Combining the organic carbon export production maps with our export ratio estimates makes it possible to provide a new set of global estimates of the particle export of all the major nutrients. We can also use the remineralization functions to estimate the cycling of this exported organic matter in the ocean interior. We are presently writing a paper describing the results of this analysis (Dume ot al., in prep.-a), and will contimue to use the results of these types of analyses to test and improve our ocean biogeochemistry models for predicting the response to fertilization. 


\section{Outreach}

During the period of this grant, we wrote a series of overview papers related to the carbon cycle of the ocean that were informed by the research that was carried out as part of this project, although they do not explicitly acknowledge any specific grant. These include: Edmonds ef ol. in press, Gruber er al, in press, Marinover al in press, and Samiento and Gruber (2002).

\section{Summary}

In concluding, we return to the set of five questions we raised in the introductory overview and use these as a template to summarize the major findings of our research with relevance to the use of fertilization to sequester $\mathrm{CO}_{2}$ from the almosphere.

(1) If iron is added to the ocean, will export of organic carbon from the surface actually occur?

Ultimately, this question must be answered by in silu experiments. However, our empirieal work on the relationship between particle export and primary production (Dwne ef al. subwitted) is certainly consistent with the general expectation that the increased primary production that has been observed in iron fertilization studies should result in increased export.

(2) If iron Fertilization does lead to export of organic carbon from the surface of the ocean, how much $\mathrm{CO}_{2}$ will actually be removed from the atmosphere?

Our short-term patch-fertilization scenarios (Gnamadesikan et al., 2003) suggest that the efficiency of small-scale iron fertilization scenarios, i.e, the fraction of increased export production that comes from the atmosphere, is likely to be extremely low (2-10\% after 100 years). This low efficiency can go as high as $40 \%$ after 100 years, but only if macronutnents (nitrate and phosphate) are added with the iron and if the iron is retained in the water column rather than scavenged, Long-tem basin-scalẹ fertilization scenarios are more efficient in preventing the carbon from escaping back to the atmosphere.

An important caveat is that the biogeochemistry model that was used for these simulations is an extremely simple diagnostic model based on forcing surface nutrients back towards observations, or to 0 in the case of the nutrient depletion scenarios. We did not include functional groups in this model, and our modeling of the iron distribution and interior remineralization of organic matter was also rudimentary. A critical issue that remains to be addressed is how our conclusions would be affected if we used a more realistic biogeochemistry model such as we developed as part of this grant (cf., Deutsch, 2003, Dunne et al, submitied, Gnanadesikan et al., subwitted, and Dunne et al., in prep.-b). Ongoing research with a renewal of this grant should enable us to implement our new biogeochemistry model and address these issues in the near future.

(3) What is the time scale of any sequestration that occurs?

The work described under (2) shows that long-term sequestration requires long-term fertilization. A major reason for the low efficiency we found in our patch-fertilization scenarios 
is because of the rapid return of the sequestered carbon back to the atmosphere at locations far awsy from the region of fertilization.

(4) Can the magnitude of sequestration be verified?

The short answer to this is very likely not, at least for the patch-fertilization scenarios (Gnandiesikan el al, 2003). Direct verification by measurement of the air-sea $\mathrm{CO}_{2}$ fluxes that result from a given fertilization event presents an insumountable challenge with present technology. The fluxes are far smaller than the natural variability, and their spatial scale, particularly the longer-tem escape of the sequestered $\mathrm{CO}_{2+}$ is vast. Indirect verification by monitoring of the actual export of organic carbon is challenging, and inferring the impact of such an export event requires a far better understanding of what determines the efficiency of sequestration than we have at present. Verification is also extremely challenging with regard to the possible offsetting effect from $\mathrm{N}_{2} \mathrm{O}$ emissions. Iim and Gruber (in press) show that the majority of the fertilization induced outgassing of $\mathrm{N}_{2} \mathrm{O}$ into the atmosphere occurs well outside the patch and continues well into the future even after fertilization has stopped.

(5) What unintended consequences might there be from fertilizing the ocean with iron?

Our research suggests that there may be quite significant negative impacts from fertilization. In the patch-fertilization scenarios, we find a long-term rectuction in biological production as nutrients are removed from the surface and sequestered at depth, unless macronutrients are added with the iron and the iron is retained in the water column (Gnanadesilan et al., 2003). Such changes in oceanic biological production are even more marked in the large-scale fertilization scenarios, where there may be as much as a $75 \%$ reduction in global expon production resulting from a Southem Ocean fertilization (Sarmiento et al, in press, and Marmov et al, in prep.-b). There is also a potentially large production of nitrous oxide, a potent greenhouse gas that may counteract much of the effect of any $\mathrm{CO}_{2}$ removal that is achieved by a given fertilization event (Jin and Gruber, in press).

\section{Students and postdoctoral researchers trained:}

- Dr, Xir Jin, Post-Doc, UCLA.

- Irina Marinov, Graduate Student, Princeton University

- Dr. Curtis Deutsch, Graduate Student, Princeton University, presently a Post-Doc at the University of Washington

- Dr. John Dunne, Post-Doc, Princeton University, presently at GFDL/NOAA

\section{Publications:}

\section{Journal and Book Articles (published, in press, and in preparation)}

Deutsch, C., 2003. Biogeochemical constraints on the modem and glacial oceanic nitrogen 
cycle. Ph.D. Thesis, Princeton University, Princeton, NJ.

Dunne, J. P., R. A. Armstrong, A. Gnanadesikan, J. L. Sarmiento, and R. D. Slater (in preparation-a) New estimates of global particle export of the major elennents and their cycling in the ocean interior. (Global Biogeochem. Cycles)

Dunne, J. P., R. A. Armstrong, A. Gnanadesikan, J. L. Sarmiento, and R. D. Slater, submitted. Empirical and mechanistic models for particle export ratio. (Global Biogeochem. Cycles)

Dunne, J. P., A. Gnanadesikan, P. Swathi, J. L. Samiento and R. Armstrong (in preparation-b) Controls on global particle export and remineralization in a global ocean general circulation model, (Global Biogeochemical Cycles)

Edmonds, J., F. Joos, N. Nakicenovic, R. Richels, and J. L. Sarmiento, in press. Scenarios, targets, gaps, and costs. In: Toward CO2 Stabilization: Issues, Strategies, and Consequences, A SCOPE/GCP Rapid Assessment Project, ed. C. Field and M. Raupach, Island Press, Washington, D.C.

Gnanadesikan, A., J. P. Dunne, R. M. Key, K. Matsumoto, J. L. Sarmiento, R. D. Slater, and P, S. Swathi, submitted. Oceanic vertical exchange and biogeochemical cycling: Comparisons between models and new observational estimates. (Global Biogeochem. Cycles)

Gnanadesikan, A., J. L. Sarmiento, and R. D. Slater, 2003. Effects of patchy ocean fertilization on atmospheric carbon dioxide and biological production. Global Biogeochem. Cycles, 17 (2), doi: $10.1029 / 2002 \mathrm{~GB} 001940$.

Gruber, N., P. Friedlingstein, C.B. Field, R. Valentini, M. Heimann, J.E. Richey, P. RomeroLankao, D, Schulze, and C.-T.A. Chen, in press. The vulnerability of the carbon cycle in the 21 st century: An assessment of carbon-climate-human interactions, In: Toward $\mathrm{CO}_{+}$ Stabilization: Issues, Strategies, and Consequences Eds: C. B. Field and M. R. Raupach, Island Press.

Jin, X., J. Dunine, C. Deutsch and N. Gruber, in prep., Diagnosing phytoplankton functional groups from global nutrient and alkalinity distributions. (Global Biogeochemical Cycles)

Jin, $\mathrm{X}$ and $\mathrm{N}$. Gruber, in prep. Constraining oceanic $\mathrm{N}_{2} \mathrm{O}$ production mechanisms by an inversion of large-scale oceanic $\mathrm{N}_{2} \mathrm{O}$ data. (Global Biogeochemical Cycles)

Jin, $\mathrm{X}$ and $\mathrm{N}$. Gruber, in press. Offsetting the radiative benefit of ocean iron fertilization by enhancing $\mathrm{N} 2 \mathrm{O}$ emissions (Geophys. Res. Lett.)

Marinov, 1., A. Gnaniadesikan, J.L. Sarniento and R.D. Slater, in preparation-a, What controls the air-sea flux of carbon dioxide? (Global Biogeochem. Cycles,) 
Marinov, I., and J. L. Samiento, in press. The role of the oceans in the global carbon cycle: An overview. In: Ocean Carbon Cycle and Climate, ed. M. Follows and T. Oguz, NATO ASI, Ankara, Turkey.

Marinov, I., J.R. Toggweiler, A. Gnanadesikan, K. Matsumoto, J.L. Samiento and R.D. Slater; in preparation-b, Impacts of nutrient depletion in general circulation nodels and box models. (Global Biogeochem. Cycles)

Sarmiento, I. L., J. Dunne, A. Gnanadesikan, R. M. Key, K. Matsumoto, and R. Slater, 2002. A new estimate of the $\mathrm{CaCO}_{3}$ to organic carbon export ratio, Global Biogeochem. Cycles, 16 (4), 1107, doi: 10.1029/2002GB001919.

Sarmiento, J.L., and N. Gruber, 2002, Sinks for anthropogenic carbon, Physics Today, August 2002 , pp $30-36$.

Samiento, J. L., N. Gruber, M. A. Brzezinski, and J. P. Dunne, in press. High latitude controls of the global nutricline and low latitude biological productivity. (Nature).

\section{Conference Abstracts:}

Dunne, J.P., R. A. Amstrong, C. Deutsch, A. Gnanadesikan, J.L. Samiento, 2002. A multielement ecosystem model for global biogeochemical cycles, Eos Trans. AGU, 83(4), Ocean Sci. Meet. Suppl., Abstract OS32L-12.

Gnanadesikan, A., J.L. Samiento, and R. Slater, 2001. Ocean fertilization and biological productivity, Proceedings, Ist National Conference on Carbon Sequestration, National Energy Technology Laboratory, Paper 6D-1.

Gnanadesikan, A., J.L. Sarmiento and R.D. Slater, 2002. Changes in atmospheric carbon dioxide and biological productivity induced by patchy fertilization, Eos Trans. AGU, 83(4), Ocean Sci. Meet. Suppl., Abstract OS51F-08.

Gnanadesikan, A., J.L. Sarmiento and R.D. Slater, 2002. Efficiency and effects of carbon sequestration through ocean fertilization, Proceedings, Sixth International Conference on Greenhouse Gas Control Technologies, Paper 13-5.

Jin, X., C. Deutsch, N. Guber, and K. Keller, 2002. Assessing the consequences of iron fertilization on oceanic $\mathrm{N} 2 \mathrm{O}$ emissions and radiative forcing. Eos Trans. AGU, 83(4), Ocean Sci. Meet. Suppl., Abstract OS51F-10.

Jin, $X$ and $N$. Gruber, 2002. Offsetting the radiative benefit of ocean iron fertilization by enhancing ocean N2O emissions, Eos Trans. AGU, 83(47), Fall Meet. Suppl., Abstract U21A-0006. 
$7 c+6 z+T^{\circ}(\mathrm{T})+\mathrm{T}+\mathrm{sap} 0$

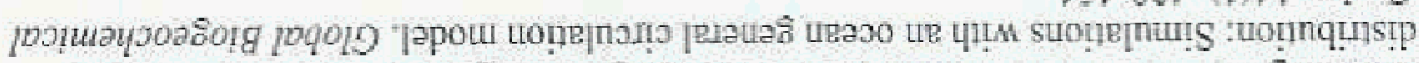

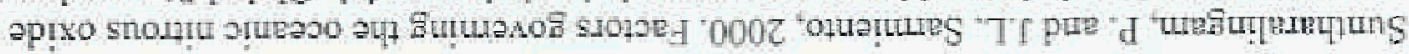

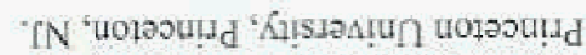

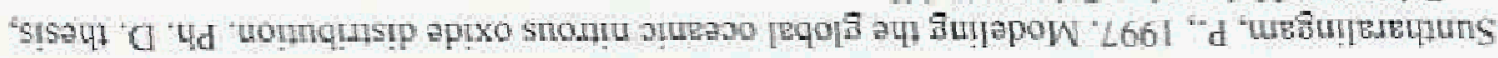

$10 L 2-189287^{\circ}$ "II -

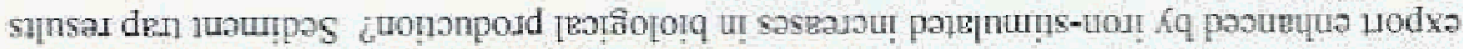
вoIIs stus

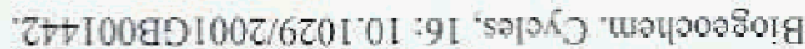

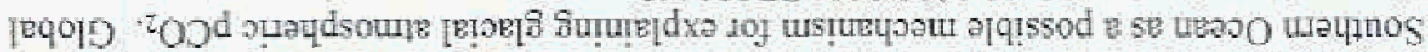

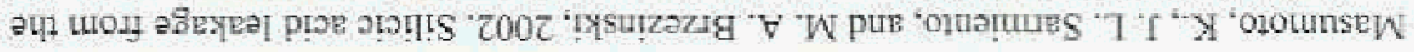

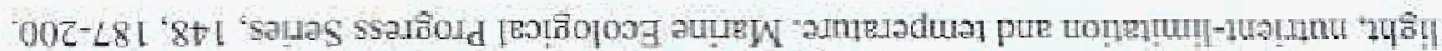

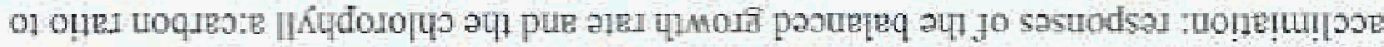

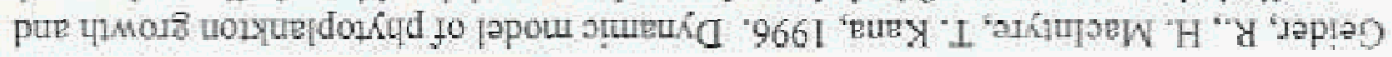

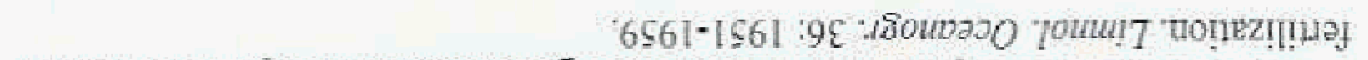

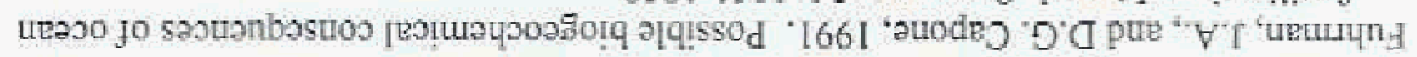

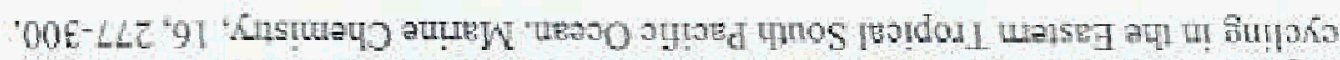

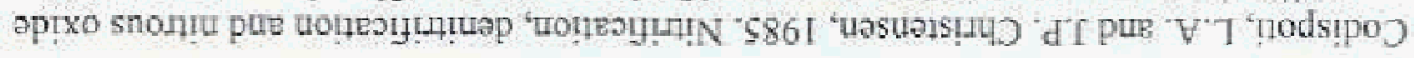

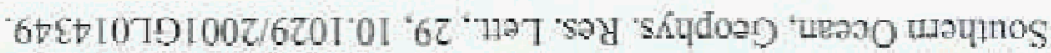

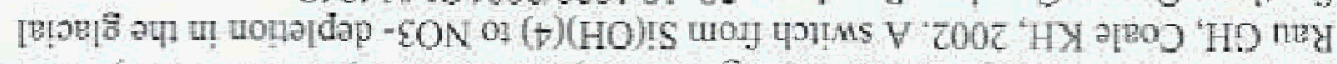

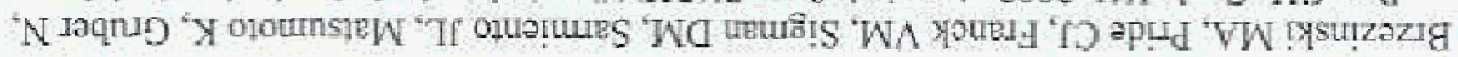

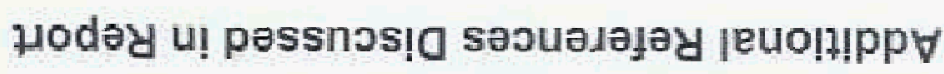

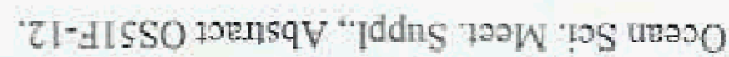

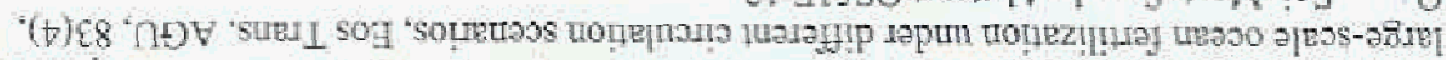

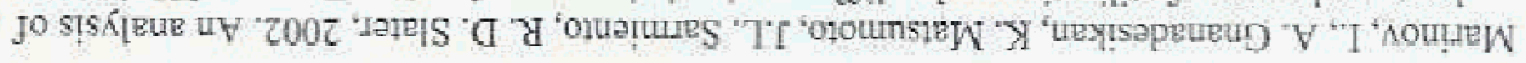

sserd ut "iddns naอN "Iog ureoo

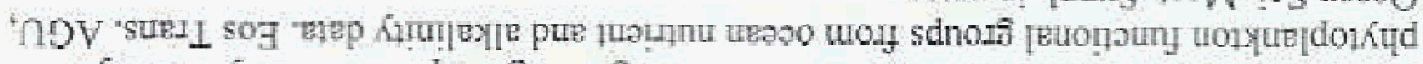

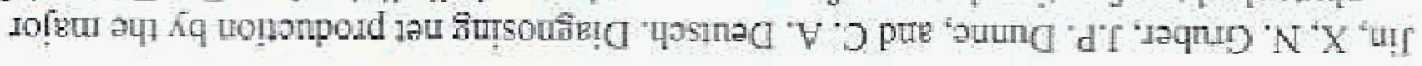

